\title{
Organizational Citizenship Behaviors and Counterproductive Work Behaviors: A Study of Tehran University of Medical Sciences Staff
}

Dargahi Hossein ${ }^{* *}$ and Koiek Somayeh ${ }^{2}$

${ }^{1}$ Department of Management Sciences and Health Economics, Health Information Management Research Center, Tehran University of Medical Sciences, Tehran, Iran ${ }^{2}$ Department of Research and Technology, Kurdistan University of Medical Sciences, Sanandaj, Iran

\begin{abstract}
Introduction: Organizational citizenship behavior (OCB) is associated with major factors such as job satisfaction and organizational commitment and productivity. However, counterproductive work behavior (CWB) as a voluntary behavior of the staff runs counter to the organizational objectives and interests. This research attempts to determine the relationship between OCB and CWB in the headquarters departments' staff of Tehran University of Medical Sciences in Iran.

Methods: This descriptive-analytical and cross-sectional research was conducted in 2015-2016 on 235 staff of Tehran University of Medical Sciences who had been selected via employing Cochran formula. The research instrument included Pudsakoff's OCB Questionnaire including five dimensions of Altruism, Conscientiousness, Sportsmanship, Courtesy and Civic virtue, and the CWB questionnaire developed by Fox and Specter. The validity of the questionnaire was confirmed through content and face validity measures while its reliability was confirmed via alpha Cronbach method. SPSS software was used for analyzing the collected data. Incidentally, the descriptive tables were presented using mean and percentages, while the analytical statistics were provided through Pearson Correlation and Spearman, T-test, ANOVA and Linear Regression Tests.
\end{abstract}

Results: The OCB was measured to be over the average and was $3.58 \pm 0.95$, and the CWB mean was $3.58 \pm 1.14$. There was a negative significant correlation between CWB and OCB $(P=0.03, r=0.382)$. The correlation analyses showed that $14 \%$ of the CWB variations could be associated with OCB.

Conclusion: Since only as little as $14 \%$ of the CWB is associated with OCB, it seems that other intra-organizational factors such as organizational justice, managers' ethics and organizational requirements could as well impact CWB and thus warrant further research.

Keywords: Organizational citizenship behavior; Counterproductive work behavior; Tehran university of medical sciences

\section{Introduction}

Organization is a social structure in which groups of individuals with different mental, social and cultural differences work to attain shared objectives [1]. To fulfill these ends, effective and efficient organizations are required [2]. Provision and enhancement of health care system is one of the challenges of governments to attain sustainable development [3]. Human resources are one of the most important resources of health care organizations if they use these resources effectively and efficiently. Therefore, considering its requirements and issues and establishing organizational climate significantly contribute to fulfill the objectives of these organizations [4].

Human resource could prove disruptive in lack of an effective leadership and run counter to the goals of their organization. This warrants the recognition of various organizational behaviors such as Organizational Citizenship Behavior (OCB) and Counterproductive Work Behavior (CWB) are of particular importance [5]. OCB is a desirable trait for health care organizations because of development of important job satisfaction and organizational productivity. Analyzing this concept provides a variety of extra-role behaviors. However, it is not organized through formal organization and reward system [6,7]. OCB allocate the organizations with more resources and at the same time reduces dependency on formal, and expensive mechanisms [8]. Therefore, if organizations desire effective practices, they need staff to be committed innovation, spontaneous ability and extra-role behaviors which are testimonies to OCB [9]. However, OCB categorize generally in five broad dimensions of Altruism, Conscientiousness, Courtesy, Civic virtue and Sportsmanship [10].
In contrast, Counter-productivity Work Behavior (CWB) as a voluntary behavior by the staff is in conflict with the interests and objectives of the organization (5). In many cases, disruptive working behavior may be in contradiction with OCB. For instance, CWB is contradicted with timely attendance at work, and consequently disruptive working behaviors such as absence, delayed attendance and evasion will be happend [11].

OCB and CWB are inversely related together, that could be associated with the staffs themselves and their performances [12]. Recognizing and understanding OCB and providing an appropriate organizational climate for their manifestation and avoidance of CWB facilitate provision of more desirable performance by the staff which results increased satisfaction by customers and enhanced organizational and individual effectiveness and efficiency [13-15]. Considering the above-mentioned arguments, this research is aimed to determine the relationship between OCB and CWB in the headquarters departments staff of Tehran University of Medical Sciences. As a matter of fact, the authors have attempted to answer the following questions:

*Corresponding author: Dargahi Hossein, Department of Management Sciences and Health Economics, Health Information Management Research Center, Tehran University of Medical Sciences, Tehran, Iran, Tel: + 009821-88989134; E-mail: hdargahi@sina.tums.ac.ir

Received May 12, 2018; Accepted June 06, 2018; Published June 11, 2018

Citation: Hossein D, Somayeh K (2018) Organizational Citizenship Behaviors and Counterproductive Work Behaviors: A Study of Tehran University of Medical Sciences Staff. Review Pub Administration Manag 6: 247. doi:10.4172/2315 7844.1000247

Copyright: ( 2018 Hossein D, et al. This is an open-access article distributed under the terms of the Creative Commons Attribution License, which permits unrestricted use, distribution, and reproduction in any medium, provided the original author and source are credited. 
1. To what extent OCB and CWB are prevalent in the headquarters departments' staff of Tehran University of Medical Sciences?

2. Is CWB significantly associated with $\mathrm{OCB}$ and its relevant dimensions in the headquarters departments' staff of Tehran University of Medical Sciences?

3. Are the demographic characteristics significantly associated with the OCB and CWB in the headquarters departments' staff of Tehran University of Medical Sciences?

\section{Materials and Methods}

This descriptive-analytical and cross-sectional research was conducted in 2015-2016 on 235 staff of Tehran University of Medical Sciences. The research population was 1912 included all members of the headquarters departments' staff of deputies for health, treatment, students' affairs, culture, education, research and technology, management development and resources planning, food and drugs, and international relations of Tehran University of Medical Sciences.

Using Cochran sampling formula at a confidence coefficient of 94\% $(\mathrm{z}=1.96, \mathrm{p}=\mathrm{q}=0.5)$ and $(\mathrm{d}=0.06), 245$ of the staff appropriate to the numbers of each deputy were selected and 235 questionnaires were completed by the respondents which yielded a response rate of $95 \%$.

Data collection instruments were Specter\& Fox's CWB [16] and Pudsakoff's OCB questionnaires [17] and the demographic characteristics information. Pudsakoff's OCB Questionnaire had twenty questions which were Altruism (1-4), Conscientiousness (5-7), Sportsmanship (8-10), Civic Virtue (11-13) and Courtesy. Likert Scale was applied for scoring as very high $=5, \mathrm{High}=4$, Medium $=3, \mathrm{Low}=2$ and Very Low $=1$. The reliability of the OCB questionnaire was assessed to be $79 \%$ among 20 members of the statistical population who had not been assigned to the final research sample. The face and content validity of this questionnaire were verified through a panel of experts consisted faculty members of Management Sciences and Health Economics Departments of Tehran University of Medical Sciences.

Specter \& Fox's CWB Questionnaire was comprised of 45 questions. Again, Likert Scale was also applied for scoring the items in following denominations: Completely Agree, Agree, No Comment, Disagree and Completely Disagree. This questionnaire categorizes the individuals and organizational counterproductive behaviors. Some of the items contained in this questionnaire are as follows:

"Pretending to be working while doing nothing in practice" and "complaining to people outside the workplace that you are working in a boring and unproductive organizational climate" as organizational counterproductive behavior, and also "mocking coworkers for their good performances" and "pointless arguments and conflicts with colleagues" as individuals counterproductive working behavior.

For this questionnaire, Fox et al. reported an alpha Cronbach of $88 \%$ and $96 \%$ for the organizational and individuals behaviors, respectively [18]. The validity of the questionnaire was verified by a panel of experts after it was translated by two English translators and then were compared by a third translator. To verify the questionnaire reliability, the researchers employed a group of 20 staff who were not involved in the study and the reliability was calculated to be $86 \%$ using by Cronbach formula.

Demographic Information of the staff including the age, gender, marital status, type of employment, place of work, monthly salary, education degree and years of work experiences collected by separate questionnaire.
The collected data was analyzed by SPSS software and the tables, average, and standard deviation were used for presenting descriptive results, and for provision of analytic results Pearson correlation test was conducted to determine the relationship between CWB and OCB and its components, T-test and Spearman and Anova test were carried out to determine the relationship between OCB and the demographic information and the Regression Analysis was used to measure the impression of OCB on CWB among the staff of Tehran University of Medical Sciences.

\section{Results}

The results of the demographic details of staff showed that the majority of them were females $(162,67 \%)$, in the age range of $30-40$ years $(96,74 \%)$, married $(179,74 \%)$, had BSc. $(179,74 \%)$, with $15-$ 25 work years experiences $(82,34 \%)$ and employed on a temporary basis $(123,51 \%)$ with an average monthly salary of 25,000,000 Rials. Moreover, while the largest portion of the staff $(41,17 \%)$ belonged to the Deputy for Development Management and Resources Planning, the smallest number of the staff $(9,3.7 \%)$, were working in the Deputy for Cultural Affairs.

The results of Table 1 indicated that the rate of OCB was at a desirable level except for courtesy. Although altruism received the highest score, but the studied staff stated that they adopted the CWB behaviors more than average.

The relationship between the OCB and gender was measured by Independent $\mathrm{T}$ test. The results revealed the average score were 3.70 and 3.45 for female and male staff, respectively. Therefore, these scores demonstrated that the females staff were more inclined to the adoption of OCB than their males counterparts $(\mathrm{P}=0.01)$. However, using Independent $\mathrm{T}$ test did not reveal significant differences between the $\mathrm{OCB}$ and the marital status of the staff $(\mathrm{P}<0.05)$. ANOVA test confirmed as well that there was no significant correlation between the OCB and the type of the employment of studied staff $(\mathrm{P}<0.05)$. Moreover, Spearman Correlation test did not capture any meaningful relationship between the education degree of the staff and their length of work experiences and the adoption of $\mathrm{OCB}(\mathrm{P}>0.05)$.

In other words, the research results revealed a significant and inverse relationship between the $\mathrm{CWB}$ of staff and their age $(\mathrm{P}=0.01, \mathrm{r}=-$ $0.35)$, education degree $(\mathrm{P}=0.01, \mathrm{r}=-0.65)$ and years of work experiences $(\mathrm{P}=0.02, \mathrm{r}=-0.275)$. In other words, with increases in age, years of work experiences as well as level of education degree, the extent of CWB behaviors tends to decrease. However, no significant relationship was found between CWB and the marital status of the staff $(\mathrm{P}>0.05)$.

Finally, using Pearson Correlation Test demonstrated a significant relationship between $\mathrm{OCB}$, and its dimensions and $\mathrm{CWB}(\mathrm{P}=0.03, \mathrm{r}=$ 0.382 ). In other words, the increase of $\mathrm{OCB}$ and its dimensions could be

\begin{tabular}{|c|c|}
\hline OCB and its dimension & Mean and SD \\
\hline Conscientiousness & $3.75 \pm 0.65$ \\
\hline Altruism & $4.93 \pm 1.39$ \\
\hline Sportsmanship & $3.23 \pm 1.03$ \\
\hline Civic virtue & $3.17 \pm 1.19$ \\
\hline Courtesy & $2.82 \pm 0.49$ \\
\hline OCB total & $3.58 \pm 0.95$ \\
\hline Organizational-associated CWB & $4 \pm 1.25$ \\
\hline Staff-associated CWB & $3 \pm 1.20$ \\
\hline CWB total & $3.45 \pm 1.84$ \\
\hline
\end{tabular}

Table 1: The status of OCB and its dimensions and CWB among the staff 
decreased the dimensions of CWB among the staff of Tehran University of Medical Sciences. Based on Pearson Correlation Test, there was a reverse and significant relationship between CWB and altruism, civic virtue and courtesy, while there was a strong and negative relationship between sportsmanship and CWB (Table 2).

Tables 3 and 4 showed, that correlation analysis confirmed the appropriateness hypothesis of the model that suggesting the impacts of OCB on CWB behaviors at a significance levels of $\mathrm{p}=0.001$. $\mathrm{R}^{2}$ coefficient in Table 4 showed that $14 \%$ of changes in CWB could be associated with OCB.

\section{Discussion}

Based on the descriptive findings of current research, OCB and its dimensions were assessed to be at a desirable level among the studied staff. Dargahi et al. [19] concluded the rate of OCB among the staff of Tehran University of Medical Sciences was at a higher-than-average level in every OCB component except for altruism. Also, Dargahi and Torabi [20] stated the rate of OCB was lower than average in the hospitals nurses of Tehran University of Medical Sciences. Ahmadi et al. [21] reported the rate of OCB was found to be lower than average among the staff of teaching hospitals of Tehran and Isfahan Universities of Medical Sciences. It seems that from 2012 up to the year of conducting this study, the rate of OCB was fluctuating in Tehran University of Medical Sciences due to changes in policies of human resources management, limited allocation of resources, and the views held by senior managers, and the types of hospitals and jobs selected.

Soon Ang et al. [22] reported the rate of OCB adoption was low in the staff of Singapore which is not consistent with the findings of current study. Moreover, Hoffman et al. [23] believed the adoption of OCB was more than an attitude issue than job performance of the staff. However, the previous studies has demonstrated OCB is associated with a number of organizational variables such as organizational equality [24], trust of the staff to the managers [25], self-management skills [26], job addiction [27], the quality of services provided in hospitals [28], empowering the staff [29], staff productivity [30], organizational commitment [31], the staff respond to the issue of inequality [32], social withdrawal of the staff [33], job satisfaction and characteristics of the staff [34], professional competence of the staff [35], organizational climate and efficiency [36], organizational support and ethical climate [37], job burnout [38], personal characteristics [39], organizational orientation [40], the organizational climate of universities [41] and the creative organizational climate among the students [42].
Other findings of this research revealed a significant relationship between OCB and gender of the staff $(\mathrm{P}=0.01)$ which is consistent with the research of Dargahi et al. [19]. In other words, female members of the staff were more likely to adopt OCB. Mayel Afshar et al. [43] claimed male staff displayed more OCB which is not consistent with the findings of this research. Although both above researches were conducted in Tehran University of Medical Sciences, but the time of study was carried out, the research community, and naturally their fields of job activity could have impacted the development of these conflicts. Also, the research findings of Fooladai et al. among nurses working in ICU and emergency departments of Kerman teaching hospitals revealed no significant relationship between the adoption of OCB by the staff and other demographic characteristics such as age, education degree and work years of experiences [44] which is consistent with the findings of current research.

This current research suggested the headquarters departments' staff of Tehran University of Medical Sciences adopt individual and organizational-associated CWB, at a more-than-average rate. Different researches confirmed CWB was associated with stressful organizational climate, job deprivation and even job dismissal [45-47], job absence or delays of staff [48] and conflicts among the staff [49]. Furthermore, Fox \& Spector as well as Storm \& Spector $[50,51]$ showed being job deprivation and organizational benefits contributed to development of CWB. Also, Lim [52] showed that lack of job security conception by the staff caused CWB. The occurrence of various CWB in different organizations of Iran has been proven by the researchers including Chehrazi et al. [53] among the headquarter staff of Tehran Bus Service [53], Gholipour et al. [54] among a public, non-governmental institution in Tehran and Babaeian et al. [55] among the headquarter police of Tehran.

It was also found out that CWB had a reverse significant relationship with age, education degree and length of work experiences among the headquarters departments'staff of Tehran University of Medical Sciences. In other words, with increases in age, years of work experiences as well as level of education degree, the extent of CWB tends to decrease. Ng \& Feldman [56] reported increase in age of staff result in reduced rate of CWB and improved staff job performance which is similar to the findings of current research. However, Quinn \& Mangione [57] suggested that there was a significant relationship between job satisfaction and CWB just among the staff aged 30 and older. Therefore, the results of current research are consistent with the above-mentioned research. However, Yoon \& Jung [58] claimed there was a relationship between CWB and the staff with more than 6.5 years of work experiences in comparison

\begin{tabular}{|c|c|c|c|c|c|c|}
\hline Correlation & Altruism & Conscientiousness & Sportsmanship & Civic virtue & Courtesy & OCB \\
\hline CWB & $\mathrm{r}=-0.394$ & $\mathrm{r}=-0.366$ & $\mathrm{r}=-0.724$ & $\mathrm{r}=-0.350$ & $\mathrm{r}=-0.267$ & $\mathrm{r}=-0.382$ \\
\hline $\begin{array}{c}\text { Level of } \\
\text { significance }\end{array}$ & 0.01 & 0.04 & 0.02 & 0.01 & 0.01 \\
\hline
\end{tabular}

Table 2: The relationship between CWB and OCB components

\begin{tabular}{|c|c|c|c|c|c|}
\hline \multirow{2}{*}{ Model } & \multicolumn{2}{|c|}{ Non-standard coefficient } & Standard coefficient & T & Sig \\
\cline { 2 - 5 } & B & $\begin{array}{c}\text { Standard } \\
\text { error }\end{array}$ & Beta & \\
\hline OCB & 0.237 & 0.038 & 0.382 & 6.19 & 0.001 \\
\hline
\end{tabular}

Table 3: Analyzing the correlation between OCB and CWB.

\begin{tabular}{|c|c|c|c|}
\hline Model & $\mathbf{R}$ & $\mathbf{R}^{\mathbf{2}}$ & Adjusted R \\
\hline OCB & 0.382 & 0.146 & 0.142 \\
\hline
\end{tabular}

Table 4: The regression model of the OCB impacts on CWB. 
with other job groups which is not consistent with the results of the current research. Cohen et al. [59] reported that CWB was related to the gender which is not consistent with the results of the current research.

Based on the last finding of current research, there was reverse significant relationship between CWB and OCB and its dimensions in the headquarters departments' staff of Tehran University of Medical Sciences. Also, the regression analyses showed that $14 \%$ of the CWB variations could be associated with OCB. Sackett et al. and Gruys et al. [60] could find the difference between OCB and CWB where CWB was inversely related to OCB [61]. Similarly, Allen and O'Brien could find a reverse relationship between the attitudes of 375 staff and their supervisors to OCB and its dimensions and organizational and individual CWB [62]. Walumbwa et al. and Saboe [63,64] stated that the positive attitude of the staff to OCB would discourage CWB among them. Other studies on the relationship between OCB and CWB indicated that these two variables may have a reverse and high relationship in some situations and low and reverse relationship under other conditions [65-69]. Fox and Spector [70] found out there were common positive views in form of active interactions between OCB and $\mathrm{CWB}$, and thus choosing one behavior would exclude the other. In some situations, these active behaviors may take place concurrently or independently. It seems that five states could prompt the staff to choose the other behavior: mental pressures at work, lack of cooperation among the staff, limited organizational resources allocation, no rewards for adoption of OCB and unjustifiable CWB. Dalal [71] believed OCB and CWB display themselves by different patterns in terms of their adoption by the staff. These types of behaviors are modified by the source of grading, the occurrence of competing issues and the options of respondents. The current perspective indicated the adoption of both OCB and CWB at an average rate among the staff of every organization. Wahyu Ariani et al. and Hafidz [72,73] reported there was a reverse average relationship between $\mathrm{OCB}$ and $\mathrm{CWB}$, and thus it seems these behaviors are separately structured, but are related to each other in some way or another.

This research had its own limitations. First, it was carried out at a certain time period and thus its results may not be consistent with other time periods. Second, the information was collected via questionnaires in form of self-assessments which may bias the results. Third, the results were obtained in the headquarters departments staff of Tehran University of Medical Sciences, and thus the results may not be interpolated to other parts of the country.

\section{Conclusion}

The current research findings show that the more positively the staffs perceive OCB, the less likely they are to adopt CWB. In other words, OCB is effective in undermining CWB. Most researches carried out in this domain confirm the results of the present research. Therefore, health care organizations need staffs that are inclined to perform extrarole or OCB in addition to their own expected functions. In other words, if the managers of organizations provide the appropriate organizational environment for the staff in which decisions are made democratically, organizational goal setting satisfies the staff, paying rewards are equitable and the barriers of effective communication are removed, they are encouraged to perform extra functions which ultimately decreases the rate of $\mathrm{CWB}$.

Considering the reverse impacts of $\mathrm{OCB}$ on $\mathrm{CWB}$, the managers of Tehran University of Medical Sciences are highly recommended to focus on developing the factors and dimensions of OCB and familiarize their staff with this theory and its benefits via establishment of training courses to minimize or prevent the occurrence of CWB in their own departments.
Since only as little as $14 \%$ of the CWB is associated with OCB, it seems that other intra-organizational factors such as organizational justice, managers' ethics, quality of work life, organizational culture, conflicts, personality and individual diversity of the staff, job stress, and leadership style could as well impact CWB and thus warrant further research in future.

\section{Acknowledgement}

This research was supported by deputy for research and technology of Tehran University of Medical Sciences within the research code and ethical code of No: 19423-15-04-91. The authors appreciate the all staff of headquarters departments of Tehran University of Medical Sciences participating in this research. The author declares that there is no conflict of interest between them.

\section{Authors' contribution}

Somayeh Koiek and Hossein Dargahi participated in the design of this study, data collection, and Hossein Dargahi interpreted the results and written the manuscript. All authors read and approved the final manuscript.

\section{References}

1. Alipour FH (2011) The relationship between organizational climate and communication skills of managers of the Iranian physical education organization. Procedia-Soc Behav Sci 30: 421-428.

2. Rashidi D, Farhodi S (2010) The study of the relationship between organizational environment and bank branch efficiency. J Dev Evol Manage 7: 53-59.

3. Asefzade S (2010) Principle of health care economic (4 $\left.{ }^{\text {nd }} E d n\right)$. Qazvin, Qazvin University of Medical Sciences Publication.

4. Vazeeree M, Esfahanee SH (2010) The relationship between organizationa climate and employees' validity and happiness: The case of Alzahra University. Quart J New Thoug Educ 6: 173-190.

5. Delgoshaie B, Tofighi SH, Kermani B (2009) The relationship between organizational climate and organizational commitment in teaching hospitals of Hamedan University of medical sciences. Horizon Med Sci 14: 60-68.

6. Rostami KZ, Tol A, Haghighi AF, Foroushani RA, Pourreza A (2015) Investigation of organizational climate and organizational commitment among Tehran University of Medical Sciences hospitals nurses. Health Syst Res 9: $32-45$

7. Rezaian A, Rahimi F (2010) Impression of procedural justice on organizational citizenship behavior by organizational reliance as a medium. Horizon Med Sci 29: 62-71.

8. Tavakoli Z, Abedi MR, Salehnia M (2011) The impression of organizational citizenship behavior on increased of organizational commitment. J Publ Admin Perspect 9: 105-124.

9. Benson THL, Loosemore M (2017) The effect of inter-organizational justice perceptions on organizational citizenship behaviors in construction projects. Int J Proj Manage 35: 95-106.

10. Hart TA, Gilstrap JB, Bolino MC (2016) Organizational citizenship behavior and the enhancement of absorptive capacity. J Bus Res 69: 3981-3988.

11. Gerke A, Dickson G, Desbordes M, Gates S (2017) The role of interorganizational citizenship behaviors in the innovation process. J Bus Res 73: 55-64.

12. Spector PE, Fox S (2002) An emotion-centered model of voluntary work behavior: Some parallels between counterproductive work behavior and organizational citizenship behavior. Human Resource Manage Rev 12: 269-292.

13. Fang CC, Sheng TS (2011) The impacts of perceived organizational support and psychological empowerment on job performance: The mediating effects of organizational citizenship behavior. Int J Hosp Manage 3: 180-190.

14. Pinder CC (2008) Work motivation in organizational behavior ( ${ }^{\text {nd }}$ Edn). USA New York: Psychology Press 1: 423-425.

15. Dalal RS (2005) A meta-analysis of the relationship between organizational citizenship behavior and counterproductive work behavior. J Appl Psychol 90: 1211-1255.

16. Spector PE, Fox S (2005) A model of counterproductive work behavior. In S Fox \& P.E Spector (Eds). Counterproductive work behavior: investigations of actors and targets. Ame Psychol Assoc 1: 151-174. 
Citation: Hossein D, Somayeh K (2018) Organizational Citizenship Behaviors and Counterproductive Work Behaviors: A Study of Tehran University of Medical Sciences Staff. Review Pub Administration Manag 6: 247. doi:10.4172/2315-7844.1000247

17. Podskoff PM, Mackenzie SB, Moorman RH, Fetter R (1999) Transformational leader behaviors and their effects on followers' trust in leader, satisfaction, and organizational citizenship behaviors. Leadership Quart 1: 107-142.

18. Fox S, Spector PE, Miles D (2002) Counterproductive work behavior (CWB) in response to job stressors and organizational justice: Some mediator and moderator tests for autonomy and emotions. J Vocat Behav 59: 291-309.

19. Dargahi H, Alirezaei S, Shaham G (2012) Organizational citizenship behavior among Iranian nurses. Iran J Publ Health. 41: 85-90.

20. Dargahi H, Torabi MM (2017) The Relationship of organizational citizenship behavior with job satisfaction and organizational commitment of nurses among public hospitals of Tehran University of Medical Sciences. Manage Strat Health Syst 2: 234-246.

21. Ahmadi AK, Mobaraki H, Yousofli M (2012) Structural relations between job satisfaction and organization citizenship behavior among nurses of Qazvin and Isfahan hospitals. Ghazvin U Med Sci J 16: 71-76.

22. Ang S, Dyne LV, Begley TM (2003) The employment relationships of foreign workers versus local employees: a field study of organizational justice, job satisfaction, performance, and OCB. J Organ Behav 24: 561-583.

23. Hoffman BJ, Blair CA, Meriac JP, Woehr D (2007) Expanding the criterion domain? A quantitative review of the OCB literature. J Appl Psychol 92: 555-566.

24. Bohlooli Zinab N, Matin AY, Derakhshan MA (2011) Investigation of organizational justice on organizational citizenship behavior among Islamic Azad University-Tabriz branch staffs in Iran. Produ Manage Quart 4: 73-108.

25. Hui CH, Lee CY, Ronsseau DM (2004) Employment relationships in China: do workers relate to the organization or to people? Organ Sci 15: 232-240.

26. Asghari P, Poor AH, Zadeh PMMSA (2012) Relationship between selfmanagement skills and organizational citizenship behavior of principals in girls' high school of urmia. Procedia-Soc Behav Sci 31: 852-855.

27. Schaufeli WB, Bakker AB (2010) Work engagement: a handbook of essentia theory and research. USA: Psychol Press 65: 204-207.

28. Kazemipour F, Mohamad S (2012) Relationship between workplace spirituality and organizational citizenship behavior among nurses through mediation of effective organizational commitment. J Nurs Soc 44: 302-310.

29. Chiang FC, Hsieh ST (2012) The impacts of perceived organizational support and psychological empowerment on job performance: the mediating effects of organizational citizenship behavior. Int J Hosp Manage 31: 180-190.

30. Gautam T, Dick VR (2005) Organizational citizenship behavior and organizational commitment in Nepal. Asian J Soc Psychol 8: 305-314.

31. Khaleh AL, Naji S (2016) The relationship between organizational commitment components and organizational citizenship behavior in nursing staff. Int $\mathrm{J}$ Med Res Health Sci 5: 173-179.

32. Mamman A, Kamoche K, Bakuwa R (2012) Diversity, organizationa commitment and organizational citizenship behavior: An organizing framework. Hum Resour Manage Rev 22: 285-302.

33. Karadal H, Saygın M (2013) An investigation of the relationship between socia loafing and organizational citizenship behavior. Procedia-Soc Behav Sci 99 206-215.

34. Pavalache-llie M (2014) Organizational citizenship behavior, work satisfaction and employees' personality. Procedia-Soc Behav Sci 127: 489-493.

35. Magdalena SM (2014) The effects of organizational citizenship behavior in the academic environment. Procedia-Soc Behav Sci 127: 738-742.

36. Shahin A, Naftchali JS, Pool JK (2014) Developing a model for the influence of perceived organizational climate on organizational citizenship behavior and organizational performance based on balanced score card. Int J Prod Perform Manage 63: 290-307

37. Huang CC, You CS, Tsai MT (2012) A multidimensional analysis of ethica climate, job satisfaction, organizational commitment, and organizational citizenship behavior. Nurs Ethics 19: 513-529.

38. Talachi KR, Gorji MB (2013) Evaluating the relationship between job burnout and organizational citizenship behavior: A study of industry, mine and trade organization employees. Arab J Bus Manage Rev 2: 50-61.

39. Mosalaei H, Nikbakht R, Tojari F (2014) The relationship between personality traits and organizational citizenship behavior on athletes. Bull Environ Pharmacol Life Sci 3: 11-15.
40. Laster SW, Meglino BM, Korsgaard AM (2007) The role of other orientation in organizational citizenship behavior. J Organ Behav 29: 829-841.

41. DiPaola M, Moran TM (2001) Organizational citizenship behavior in schools and its relationship to school climate. J Sch Leadership 11: 424-447.

42. Akturan A, Cekmecelioglu HG (2016) The effects of knowledge sharing and organizational citizenship behaviors on creative behaviors in educational institutions. Procedia-Soc Behav Sci 235: 342-350.

43. Afshar MM, Pourreza A, Memarpour M (2014) The impression of demographic characteristics on organizational citizenship behavior among Tehran University of Medical Sciences teaching hospitals' staff. J Hosp 12: 51-65.

44. Fooladvandi M, Esmaeil MR, Tofighi M, Fooladvandi GH, Ramazani M (2014) The relationship between job satisfaction and organizational citizenship behavior: A study on nurses working in intensive care units and emergency departments of hospitals affiliated to Kerman University of Medical Sciences in 2012. J Health Dev 3: 341-350

45. Brockner J, Konovsky M, Cooper RS, Forger R, Martin C, et al. (1994) Interactive effects of procedural justice and outcome negativity on victims and survivors of job loss. Acade Manage Rev 37: 397-409.

46. Jacebson D (1987) A personological study of the job insecurity experience. Soc Behav 2: 143-155.

47. Burroughs SM, Bing MN, James LR (1999) Effects of personality and job stressors on affective reactions and aggressive work behaviors. Paper presented at the Amarican Psychological Assosciation and the Natioan Institute for Occupational safety and Health interdisciplinary conference on work, stress, and Helath, Beltimore, MD.

48. Chisholm RP, Kasl SV, Eskanazi B (1983) The nature and predictors of job related tension in a crisis situation: reactions of nuclear workers to the three miles Island accident. Acad Manage J 26: 385-405.

49. Chen PY, Spector PE (1992) Relationships of work stressors with aggression withdrawal, theft and substance use: An exploratory study. J Occup Organ Psychol 65: 177-187.

50. Fox S, Spector PE (1999) A model of work frustration-aggression. J Organ Behav 20: 915-931.

51. Storm PL, Spector PE (1987) Relationships of organizational frustration with reported behavioural reactions: The moderating effect of locus of control. J Occup Psychol 60: 227-234.

52. Lim VKG (1996) Job insecurity and its outcomes: moderating effects of workbased and nonwork-based support. Hum Relation 49: 171-194.

53. Chehrazi S, Gholipour A, Piran Nejad A (2015) The impression of servan leadership style on staffs' counter productive work behavior. Organ Behav Stud Quart 4: 99-118.

54. Gholipour A, Pourezat AA, Saeidinejad M (2009) The causative factors of counter productive work behavior. Irani Manage Sci Quart 2: 1-29.

55. Babaeian A, Samani Y, Karami Z (2015) The relationship between personality characteristics and job performance of Tehran Police centers' staffs. NAJA Hum Resour 37: 9-27

56. $\mathrm{Ng}$ TWH, Feldman DC (2008) The relationship of age to ten dimensions of job performance. J Appl Psychol 93: 392-423.

57. Mangione TW, Quinn RP (2017) Job satisfaction, counterproductive behavior and drug use at work. Ame Psychol Ass 60: 114-116.

58. Jung HS, Yoon HH (2012) The effects of emotional intelligence on counterproductive work behaviors and organizational citizen behaviors among food and beverage employees in a deluxe hotel. Int J Hosp Manage 31: 369378.

59. Cohen TR, Panter AT, Turan N (2013) Predicting counterproductive work behavior from guilt proneness. J Bus Ethics 114: 45-53.

60. Gruys ML, SackettP(2003) Investigating the dimensionality of counterproductive work behavior. Int J Selection Assess 11: 30-42.

61. Sackett PR, Berry CM, Wiemann SA, Laczo RM (2006) Citizenship and counterproductive behavior: Clarifying relations between the two domains. J Hum Perform 19: 441-464.

62. O' Brien KE, Allen TD (2007) The relative importance of correlates of organizational citizenship behavior and counterproductive work behavior using multiple sources of data. J Hum Performa 21: 62-88. 
Citation: Hossein D, Somayeh K (2018) Organizational Citizenship Behaviors and Counterproductive Work Behaviors: A Study of Tehran University of Medical Sciences Staff. Review Pub Administration Manag 6: 247. doi:10.4172/2315-7844.1000247

63. Walumbwa OF, Hartnell CA, Oke A (2010) Servant leadership, procedural justice climate, service climate, employee attitudes, and organizational citizenship behavior: A cross-level investigation. J Appl Psychol 95: 517-529.

64. Saboe KN (2010) Prioritizing those who follow: Servant leadership, needs satisfaction, and positive employee outcomes. Graduate theses and dissertations 1-97.

65. Bennet RJ, Stamper C (2002) Corerate citizenship and deviancy: a study of discretionary work behavior. Inc. Ryan VM. International research in the business disciplines: strategies and organization in transition 13: 265-284.

66. Sacket PR, De Veve CJ (2001) Counterproductive behaviors at work. In N. Anderson, D Ones, H.Sinangil, \& C. Viswesvavan (Eds), Handb Ind Work Organ Psychol 1: 145-164.

67. Dunlop DP, Lee K (2004) Organizational citizenship and workplace devian behavior? Are they distinct?. J Organ Behav 25: 67-80.

68. Keuoway EK, Loughlin C, Barling J, Nault A (2002) Self $\square$ reported counterproductive behaviors and organizational citizenship behaviors: Separate but related constructs. Int J Sele an Asses 10: 143-151.
69. Sacket PR, Berry CM, Wiemann SA, Laczo RM (2009) Citizenship and counterproductive behavior: clarifying relations between two domains. Hum Perform 19: 441-464.

70. Spector PE, Fox S (2010) Counterproductive work behavior and organizational citizenship behavior: are they opposite forms of active behavior? Appl Psychol 59: 21-39.

71. Dalal RS (2005) A meta-analysis of the relationship between organizational citizenship behavior and counterproductive work behavior. J Appl Psychol 90: 1241-1255.

72. Ariani WD (2013) The relationship between employee engagement, organizational citizenship behavior, and counterproductive work behavior. Int J Bus Admin 4: 46-56.

73. Hafidz WM, Hoseini SM, Fatimah O (2012) The relationship between organizational citizenship behavior and counterproductive work behavior. Asian Soc Sci 8: 32-37. 